\title{
Melding Multiple Sources of Knowledge: Using Theory and Experiential Knowledge to Design a Community Health Intervention Study
}

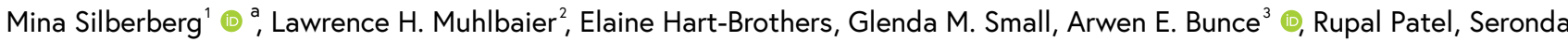 \\ Robinson $^{4}$ (1), Sherman A. James ${ }^{5}$ (1) \\ ${ }^{1}$ Family Medicine and Community Health, Duke University School of Medicine, ${ }^{2}$ Biostatistics and Bioinformatics, Duke University School of Medicine, ${ }^{3}$ OCHIN, \\ Inc., ${ }^{4}$ Public Health Education, North Carolina Central University, ${ }^{5}$ Sanford School of Public Policy, Duke University \\ Keywords: theory, health inequities, cbpr \\ https://doi.org/10.35844/001c.29013
}

\section{Journal of Participatory Research Methods}

Vol. 2, Issue 3, 2021

\begin{abstract}
Although Community-Based Participatory Research (CBPR) is grounded in socioecological theories of health, using and addressing theory in CBPR can be challenging. This paper explores how theory was used and melded with community expertise in one CBPR study in Durham, North Carolina. Challenges to use of theory included time restrictions, the need to focus on meeting local needs and making short-term measurable gains, and differences among collaborators in comfort with and concern for theoretical discussion. Both community and theoretical voices were sometimes short-changed - particularly voices that were more difficult to access or integrate into existing ways of operating. Nonetheless, we were able to bring theory into our work at a number of stages and to meld theory with community expertise in ways that benefited our project. Our case study suggests the importance of creating opportunities for small group discussion; utilizing an iterative dialogic approach to melding theory and community expertise; grounding theoretical discussions in specific, concrete questions; taking the long view of CBPR, including purposefully bringing attention to theory even while responding to pragmatic concerns; and spending more time on building the capacity to collaborate of both academic and community partners. It also raises the need for funders to consider how to align their expectations of grantees with effective attention to root causes of poor health and health disparities.
\end{abstract}

\section{Background}

Melding the knowledge of researchers and community members is central to community-based participatory research (CBPR). However, greater attention is needed to the challenges of and strategies for doing this. This paper focuses specifically on the use of social science theory in one CBPR project and how it was melded with community expertise. It begins with background on the importance of this topic followed by the presentation and discussion of a case study. All research presented was approved by the Duke Medicine or North Carolina Central University Institutional Review Boards. The authors of this paper include both community and academic members of the study team.

\section{Community-Based Participatory Research}

CBPR is "a partnership approach to research that equitably involves, for example, community members, organizational representatives, and researchers in all aspects of the research process and in which all partners contribute

\footnotetext{
a Correspondence regarding the article should be directed to Mina Silberberg, Duke University Division of Community DUMC 104652 Durham, NC 27710; mina.silberberg@duke.edu
} 
expertise and share decision making and ownership" (Israel et al., 1998). CBPR aims to use and increase knowledge in a way that directly benefits the community by improving the relevance and quality of research, empowering community members through their research leadership, and ensuring that community members are adequately compensated and community interests are taken into consideration throughout the research process. In fact, a growing body of literature indicates that CBPR can: 1) enhance the cultural appropriateness of research; 2) improve study recruitment; 3) provide important insights into community needs and context; 4) strengthen the likelihood of community benefit from research; 5) promote sustainability of successful work and adaptation to other contexts; and 6) expand the capacity of researchers and community members to work together, taking on larger challenges over time (Brakefield-Caldwell et al., 2015; CDC Community Engagement Task Force, 2011; Israel et al., 2019; Jagosh et al., 2012; Lucero et al., 2018).

While the case for community-capacity building and research enhancement through CBPR is strong, there is a need for more attention to how it can be done most effectively (Lucero et al., 2018). As noted by Arrietta and colleagues (2017), engaging effectively in CBPR requires that academics build a new set of competencies. At the same time, Jiménez-Chávez et al. (2018) note that community participation in CBPR projects is often limited to specific tasks - such as recruitment - and there is still little empirical research on how to increase the capacity of community members to more fully engage in CBPR. Among the issues requiring attention is how to meld different knowledge sources for CBPR.

\section{Theory and CBPR}

The focus of this paper is how formal theory, in this case social science theory, was melded with community expertise in one CBPR project. As defined by Ellen Hertz (2016, p. 153):

Theory is careful generalization and parsimonious abstraction, on the basis of observation of, and interaction with, concrete social situations, which are then systematized through comparison with the generalizations of other social scientists and through a historicized examination of how our own ideas develop [...]. It is through 'theory' that we can move from singular, commonsensical apprehensions of the social world to more general, critical understandings.

Arguably, whether consciously or unconsciously, human beings generally operate on the basis of theories about how the world works, theories of the form "when a person does $\mathrm{x}$, the result will be $\mathrm{y}$." What we mean by theory in the context of this paper, however, is the formal type of theory associated with 
the academic enterprise, in which variables are defined, propositions about the relationships of variables are explicit, and theory is developed and tested through research. ${ }^{1}$

There is a need for explicit attention to effective strategies for what we have termed the "melding" of theory and community expertise. Melding can take the form of identifying and applying common insights from theory and community expertise, using one source to refine the practice implications of another (e.g., leveraging community expertise to identify the action implications of theory most appropriate for a given context), or identifying and querying contrasting insights from the two sources (which can also potentially lead to theory modification).

In many ways, theory is central to CBPR. The latter is grounded in academic theories that emphasize societal power imbalances, and many see CBPR as an antidote to atheoretical research that focuses on proximate causes of health problems instead of uncovering and addressing more fundamental causes (Wallerstein \& Duran, 2003, 2006; Williams \& Jackson, 2005). Ideally, CBPR makes researchers and community members increasingly aware of the larger socioecological framework - policies, social relationships, politics, built environment - that affects health, thereby enriching our understanding of how the world works (Stokols, 1992). Developing good theory and good practice are complementary goals. CBPR contributes to theory-building by generating culturally-appropriate concepts that provide a more accurate understanding of phenomena and by providing information on the role of context in study outcomes (AHRQ, 2004; Cargo \& Mercer, 2008; Macaulay et al., 2011; Sallis et al., 2008). Conversely, theory can strengthen practice by pointing practitioners to important factors to consider in designing and carrying out effective practice (Bradbury \& Reason, 2003; Cargo \& Mercer, 2008). As noted in an influential source, CBPR:

...integrates and achieves a balance between knowledge generation and intervention for the mutual benefit of all partners; focuses on the local relevance of public health problems and on ecological perspectives that attend to the multiple drivers of health. (Israel et al., 2005, p. 1464)

CBPR can help make theory a tool for communities to address the conditions affecting their health, but only if it is accessible and appropriate.

However, effectively using and developing theory can be challenging within the context of CBPR. First, a central insight of CBPR is that the academic world does not have all the answers. CBPR recognizes that community

\footnotetext{
1 This is not to say that academics operate only on the basis of theory. Certainly, academics are also influenced by their experience and (often unconscious) worldviews. The question for this paper is how theory and community expertise are melded in CBPR, but there is much to be said about the way that the life experience of academics influences their contributions to CBPR. It is also worth noting that there are other ways of understanding theory than the formal academic theory that is the focus of this paper. A "theory of change," for example, describes the logic of a specific initiative and does not make a claim to larger generalizability.
} 
expertise is often an important complement and even corrective to theory (Garland et al., 2006). Therefore, theory must not just be used; it must be melded with other forms of knowledge - most importantly, community expertise. Bringing together multiple sources of knowledge, however, is a challenging endeavor. Second, if CBPR is to be effective in meeting the needs of a specific community, it cannot be focused only on the generalities that theory can explain across multiple communities but must be attentive to the details of what is happening in the community, including what theory cannot yet explain. ${ }^{2}$ This is one of the reasons that CBPR emphasizes learning from the expertise of community members, who understand how things work and how to get things done in their particular context.

Third, a project team must decide how best to use its limited time. Time spent on thinking about theory might be better used in building collaborative relationships (although there may sometimes be ways to do this while thinking about theory) or meeting immediate community needs. A fourth problem arises from differences between academics and community members in their comfort with the language of theory, developing theory, and using theory to think about daily life (Chataway, 1997; Jones \& Wells, 2007); moreover, academics are paid to use their time in this way. Finally, the value of community benefit underlying CBPR, the need to keep all partners engaged, and funders' concern with seeing measurable impact all favor spending time on achieving immediate practical outcomes rather than theory-building (Adams et al., 2004; Freeman et al., 2006; Wallerstein et al., 2005).

This paper looks at the use of theory in one CBPR study - the African American Health Improvement Partnership (AAHIP) Diabetes Improvement Project — asking specifically:

1. How was theoretical knowledge utilized in this case?

2. How were theory and community expertise "melded" in study design, analysis/interpretation and dissemination? What approaches were used in this process?

3. How successful were these approaches in advancing the work?

The paper focuses on stages of the project at which the use of theory was most relevant: the writing of the original grant proposal and later intervention/ study development, analysis/interpretation and dissemination, and the subsequent work of team members.

\footnotetext{
2 Even within research, there is a tension between "nomothetic" and "idiographic" approaches. Nomothetic researchers seek to create theory, asking for example, "What is social class?” Idiographic researchers seek to fully explain a single phenomenon, e.g., "What does social class look like among African Americans in Durham?” These approaches can be combined, but through a time-consuming theory-building process (Przeworski \& Teune, 1970).
} 


\section{Case Description}

\section{Project Overview}

In September 2005, the Division of Community Health in the Duke University Department of Community and Family Medicine (now the Department of Family Medicine and Community Health) was awarded a three-year planning grant through the National Center (now Institute) for Minority Health and Health Disparity program "Community Participation in Health Disparities Intervention Research.” AAHIP used a CBPR approach to plan and pilot an intervention to improve the health of African Americans in Durham, North Carolina. The research team (RT) included researchers from Duke University and two health care providers from a local community organization, the Community Health Coalition (CHC). A 15-member Community Advisory Board (CAB) was created to represent a spectrum of Durham's African-American and health care communities, e.g., providers, community advocates, ministers, and government officials. Two professors from North Carolina Central University, a local, historically black university, evaluated the collaboration over time by surveying both $\mathrm{CAB}$ and $\mathrm{RT}$ members.

Planning and decision-making for this study resulted from deliberation by and consensus among the members of the $\mathrm{CAB}$ and the RT. Through a planning process during the pilot phase, the $\mathrm{CAB}$ and $\mathrm{RT}$ decided to address type 2 diabetes management through a project we called the Diabetes Improvement Project (DIP) and designed an intervention combining individual patient-centered health coaching by professional community health educators (CHEs) with lay-led peer support groups. A survey and biological data collection were designed to capture participant characteristics and anticipated six-month changes in knowledge, attitudes, behavior, and biological outcomes.

Based on the three-year pilot, we were awarded a full implementation grant of five years using the same general approach with some modifications. When the five-year grant period ended, the coalition stayed together for several months to decide on next steps. In the end, some members of both the CAB and RT joined a new funded community-wide diabetes initiative; subsets of the group have worked together on other projects; and members of the team continue to work together to disseminate study findings and lessons learned from the study.

While the focus of this paper is on the melding of theory and community expertise for this project, we recognize that any success in that aspect of our collaboration is premised on our ability to collaborate more generally. We believe that bonds of trust and connection were developed in this project in a number of ways; in particular, we would note the inclusion of community members on the RT and periodic participation in fun activities like celebratory events and social dinner. We also believe that the kind of collaboration we are about to describe was undertaken in a spirit of honesty and common purpose that contributed to those bonds. Thus, a relationship of trust and connection 
was both a foundation for and the result of the story we tell here. Additionally, the inclusion of community members on the RT made possible the iterative attention to community voice and the attention to clarity of communication with the $\mathrm{CAB}$.

\section{Grant Proposal}

The original grant proposal was written in broad strokes, with initial drafts written by the academics on the RT and major ideas shared with and approved by the CHC. The proposal was grounded in the socio-ecological model of health, and given compelling prior research on the efficacy of social support to foster positive health behaviors (Heaney \& Israel, 1997), improve disease management (Ford et al., 1998), and buffer daily life stressors (House et al., 1988), we tentatively proposed that increasing access to social support would be a promising platform to mount a CBPR intervention.

The proposal also expressed the likelihood that the project would address diabetes or hypertension - common diseases with which the RT had experience and that have disparate prevalence and sequelae for African Americans and Whites. Finally, the proposal indicated that the team would address the health of African Americans across the spectrum of social "class" because racial health disparities exist at all socioeconomic status (SES) levels. There is little research on groups with higher SES, and Durham has an unusually large high-SES African-American community. Researchers had also been influenced by literature on the importance for low-resource communities of "bridging social capital," i.e., social capital developed between different sectors of society (Putnam, 2001) and the proposition found in institutionalist theory ${ }^{3}$ that political sustainability of programs and policies is enhanced when those policies or programs benefit multiple sectors, e.g., rich and poor (Skocpol, 1995). In writing the proposal, then, the RT drew on multiple theoretical frameworks: the socioecological model, theories of the influence of social support on health, social capital theory, and institutionalist theory of social policymaking.

\section{Study Design}

In the early days of study design, our primary goal was designing an intervention. At the beginning of this process, we utilized what we would now describe as a collective deliberative approach, through which the team collectively considered information to move towards our goal. The study's RT met weekly to prepare for monthly $\mathrm{CAB}$ meetings and to work out the details of broad decisions made in those meetings. By definition, because RT meetings and $\mathrm{CAB}$ meetings involved both academics and community members in a highly participatory and deliberative process, this process engaged ideas grounded in both academic theory and community expertise. Initially, we

\footnotetext{
3 As illustrated in the article cited here, institutionalist theory posits that policymaking and other sociopolitical decisions are shaped by
} institutional arrangements that may themselves be the result of prior decisions. 
allocated time to sharing selected literature on diabetes management, disease prevalence and disparities data, and team members' experiences with/ observations about diabetes management.

Given the need to quickly design and launch an intervention study, however, we focused on more applied literature (describing the operational aspects of diabetes management interventions) and rarely ventured into explicitly theoretical discussions. Moreover, while weekly discussions within the RT allowed time for fruitful explanation and collective consideration of team members' perspectives, $\mathrm{CAB}$ meetings were not optimally structured early on, with RT questions often being too theoretical, abstract, or too broad (e.g., how social support could help with diabetes management) to generate effective decision-making.

One meeting, however, represented a major turning point in the RT/CAB working relationship. Both $\mathrm{CAB}$ and $\mathrm{RT}$ members shared their experiences as either people with diabetes, family members and friends of people with diabetes, or health care providers who had patients with diabetes. This particular conversation tangibly raised the level of comfort and cohesion in the group. Moreover, the RT realized that common themes had emerged from the discussion and that these could form the basis of an intervention.

Gradually, an iterative dialogic approach to intervention planning was emerging. (See Table 1 for a summary of this and other melding strategies described in this paper.) The RT worked to distill the themes that had arisen during the $\mathrm{CAB}$ meetings into core intervention elements that were then brought to the $\mathrm{CAB}$ for modification and approval. Many members of the RT brought their own theoretical insights to this process; at the same time, the RT worked to keep the presentation of themes grounded and clear, with community members being particularly important in that effort. The CAB responded enthusiastically and effectively to the request for feedback, eventually resulting in the approval of the following five intervention elements: 1) Using the church as the key setting for recruitment and intervention; 2) Strengthening social support; 3 ) Responding to participants' individual needs; 4) Offering positive messages, e.g., living well with disease is an achievement; and 5) Empowering patients to manage their condition and shift patientprovider relationships.

The RT then created and brought to the CAB for feedback a "roadmap" of specific interventions reflecting the five core elements and the anticipated intermediate and ultimate outcomes of these interventions. Without requiring the $\mathrm{CAB}$ to engage in an explicitly theoretical discussion, the development of this roadmap represented the melding of theory-based knowledge and community expertise; it spelled out a concrete intervention and couched it in a theoretical framework. Ultimately, a larger summary document organized around the five core elements of the intervention approach was produced. We described the rationales for each element to be found in community expertise and theory and specified ways in which these core elements would be reflected in our intervention. For example, an emphasis on social support was indicated 
Table 1. Melding Strategies and Examples

\begin{tabular}{|c|c|c|}
\hline STRATEGY & PROCESS & EXAMPLES \\
\hline \multirow[t]{2}{*}{$\begin{array}{l}\text { Iterative, } \\
\text { dialogic } \\
\text { approach to } \\
\text { intervention } \\
\text { development }\end{array}$} & \multirow{2}{*}{$\begin{array}{l}\text { - Moved from discussion of } \\
\text { community experience to } \\
\text { theory-informed distillation } \\
\text { of themes from discussion to } \\
\text { create core intervention } \\
\text { elements to identification of } \\
\text { specific interventions based } \\
\text { on elements and available } \\
\text { resources. } \\
\text { - All discussion was grounded } \\
\text { in practical question of how } \\
\text { to help participants manage } \\
\text { diabetes. } \\
\text { - RT (including community } \\
\text { members) initiated and } \\
\text { participated in discussion } \\
\text { while listening actively; } \\
\text { drafted written plans. } \\
\text { CAB had continuous } \\
\text { opportunities for input } \\
\text { during the iterative process. } \\
\text { RT developed } \\
\text { documentation linking core } \\
\text { elements, rationale in theory } \\
\text { and community expertise } \\
\text { and specific interventions. }\end{array}$} & $\begin{array}{l}\text { Example 1: Concordance of theory and community expertise. } \\
\text { CAB members noted that in their experience support from others, } \\
\text { particularly peers, helps with disease management. RT knew literature linking } \\
\text { social support to positive health behaviors, improved disease management, } \\
\text { and buffering of daily life stressors. Result: Strengthening of social support as } \\
\text { core intervention element; CAB approved. Two specific interventions: CHEs } \\
\text { worked with clients to strengthen individual social support and peer groups } \\
\text { primarily based on existing social networks. }\end{array}$ \\
\hline & & $\begin{array}{l}\text { Example 2: Reconsideration of theory-derived intervention based on } \\
\text { community expertise. } \\
\text { Based on the literature on the importance of "place" as a social determinant of } \\
\text { health the RT suggested a neighborhood-based intervention. CAB indicated } \\
\text { that the role of neighborhoods in community's social life had declined and } \\
\text { neighbors would not want to discuss their health with each other. They noted } \\
\text { that churches are where people spend most of their time and get most of their } \\
\text { support. Result: Church-based intervention. }\end{array}$ \\
\hline $\begin{array}{l}\text { Proactive } \\
\text { attention to } \\
\text { partnership } \\
\text { process }\end{array}$ & $\begin{array}{l}\text { - Third party conducted } \\
\text { annual survey of CAB and } \\
\text { RT. } \\
\text { - Third party presented } \\
\text { findings to CAB and RT with } \\
\text { attention to clear } \\
\text { communication. } \\
\text { - CAB and RT revised } \\
\text { partnership process. }\end{array}$ & $\begin{array}{l}\text { Survey found higher-SES African-American community overrepresented on } \\
\text { the CAB and lower-SES board members were often reluctant to speak. Result: } \\
\text { CAB and RT revised process to include full CAB participation in agenda- } \\
\text { setting, solicitation of remarks from all CAB members, establishment of } \\
\text { subcommittees, and more balanced CAB recruitment, inclusive of former } \\
\text { study participants. }\end{array}$ \\
\hline \multirow[t]{2}{*}{$\begin{array}{l}\text { Data- } \\
\text { grounded } \\
\text { multisource } \\
\text { discussion }\end{array}$} & \multirow[t]{2}{*}{$\begin{array}{l}\text { RT prepared presentation of } \\
\text { study findings to CAB with } \\
\text { attention to clear } \\
\text { communication. } \\
\text { - Discussion of meaning of } \\
\text { study findings combined } \\
\text { observations/insights of } \\
\text { CHEs, CAB, and RT. }\end{array}$} & $\begin{array}{l}\text { Example 1: Review of pilot and early full intervention findings to modify } \\
\text { intervention. } \\
\text { CAB-RT discussion of quantitative findings on participant SES and results of } \\
\text { qualitative interviews with group leaders and focus groups with clients. } \\
\text { Result: Broadening of recruitment beyond mainstream churches to smaller } \\
\text { churches and other community settings. }\end{array}$ \\
\hline & & $\begin{array}{l}\text { Example 2: Interpretation of final results. } \\
\text { Discussion of findings on changes in health status, including observations of } \\
\text { CHEs re: barriers faced by clients, stories of successful change, and insights of } \\
\text { RT and CAB. Result: Set stage for discussions of social drivers of health, } \\
\text { effectively blending theoretical frameworks and the CAB's knowledge of the } \\
\text { local conditions. Influenced member future work. }\end{array}$ \\
\hline $\begin{array}{l}\text { Focused } \\
\text { multimodal } \\
\text { contributions } \\
\text { to } \\
\text { dissemination } \\
\text { product }\end{array}$ & $\begin{array}{l}\text { CAB and RT developed } \\
\text { dissemination product } \\
\text { grounded in a specific } \\
\text { question or topic. } \\
\text { - Product was developed } \\
\text { through combination of } \\
\text { scholarly drafting, informal } \\
\text { written commentary, and } \\
\text { oral discussion, with each } \\
\text { participant using the } \\
\text { approach most comfortable } \\
\text { for them. }\end{array}$ & $\begin{array}{l}\text { Development of a manuscript on the role of SES in study recruitment, } \\
\text { retention, and outcomes allowed community members to provide comments } \\
\text { in whatever ways suited them. Sample result: Manuscript benefited from a } \\
\text { community member's close attention to the very specific needs of lower SES } \\
\text { participants; contributed as comments. }\end{array}$ \\
\hline
\end{tabular}


by both $\mathrm{CAB}$ experience and research evidence, the feasibility of changing social support in the short term, and the potential sustainability of peer support groups. Based on these rationales, we determined that CHEs would work with clients to enhance sustainable sources of support, and peer support groups would be built on existing support systems.

The story of decisions around two of the study's central concepts - social support and social capital - is useful for illustrating the benefits of melding knowledge sources in this iterative, dialogic fashion and of keeping conversations focused and grounded in practical questions. These stories also illustrate the potential of this iterative dialogic approach to allow for reconsideration of theory-based intervention elements as a result of community-expertise. For example, based on the literature on the importance of "place" as a social determinant of health (Bernard et al., 2007; Gaskin et al., 2019), the RT suggested a neighborhood-based intervention. However, the $\mathrm{CAB}$ indicated that the role of neighborhoods in Durham's social life had declined in the preceding decades, and that neighbors would not want to discuss their health with each other. They noted that churches, and, to a lesser extent, workplaces are where people spend most of their time and get most of their support, an insight that resulted in the first of our five core elements. Without an explicitly theoretical discussion, then, the CAB assessed our theory-based proposal in light of their community expertise. The CAB's insights were further supported by our baseline survey results; data from that survey showed respondents were much more likely to seek support for diabetes management from co-congregants than from friends or neighbors.

A second example can be found in how we translated the concept of "bridging social capital" for the design of our intervention. Because of our interest in creating bridging social capital - in this case, developing an intervention in which both rich and poor would have a stake - researchers hoped that support groups would be a vehicle for bringing together diabetics of different SES levels and were interested in bringing together congregants from churches that catered to different SES groups. However, the CAB argued for building on existing social networks and warned against removing people from their comfort zones. In churches with a socioeconomically diverse congregation, support groups would automatically cross SES groups. However, the $\mathrm{CAB}$ suggested that groups from homogeneous churches should be left homogeneous if we wished to make our support groups inviting and effective, and we proceeded on this basis. Again, through this approach, the $\mathrm{CAB}$ was able to appraise theory-based ideas in light of community expertise. Through the iterative, dialogic melding of theory-based knowledge and community expertise, therefore, social support and social capital remained important study constructs, but we became more realistic about their practice implications in the local context.

It is important to note that it was not only the application of theory-based knowledge that was restricted by practical considerations. There were also instances when considering, and then applying, the full range of community 
expertise proved challenging. As planning came to an end, the external evaluators administered their first collaboration survey to the CAB and RT. They found high levels of satisfaction with the effectiveness, fairness, and openness of the collaboration. However, a concern was expressed that Durham's higher-SES African-American community was overrepresented on the $\mathrm{CAB}$ and that lower-SES board members were often reluctant to speak, indicating that segments of the community had an unequal "voice" in the planning process. Having been proactive in reviewing our partnership process through the survey allowed us to improve channels for lower SES community expertise to be melded into our work. The $\mathrm{CAB}$ developed a number of measures to address this concern, including full $\mathrm{CAB}$ participation in agenda setting, solicitation of remarks from all $\mathrm{CAB}$ members, establishment of subcommittees, and more balanced $\mathrm{CAB}$ recruitment, including of diverse former study participants. Participation in meetings broadened and concern about socioeconomic diversity was not prominent in subsequent collaboration surveys.

The impact of community expertise was also enhanced by planned focus groups with pilot participants and interviews with pilot support group leaders. Preliminary results from the survey and this qualitative research were prepared by the RT to be reviewed by the $\mathrm{CAB}$, with attention to clarity of communication. When discussed collectively by the $\mathrm{CAB}$ and $\mathrm{RT}$, the results led to some practical modifications for the full-implementation study, such as broadening recruitment beyond mainstream churches to smaller churches and other community settings.

\section{Analysis, Interpretation, and Dissemination}

Use of theory was salient as we moved into data analysis, academic and community dissemination of our findings and lessons learned, and consideration of next steps. As with study design, we found that, within the $\mathrm{RT}$, we effectively combined the perspectives and priorities of both researchers and community members in data analysis planning and interpretation of findings and were sometimes effective at doing this in $\mathrm{CAB}$ meetings as well. The RT developed presentations of study results for the $C A B$ with an emphasis on clarity of communication, pairing tables and figures with bottomline findings and focusing on specific questions. One in-depth discussion of findings on changes in health status and its correlates included trenchant observations from the CHEs about changes they saw in some participants and the barriers to change faced by others. The data and these observations helped set the stage for discussions of social drivers of health, effectively blending theoretical frameworks and the CAB's knowledge of the local culture and conditions.

$\mathrm{CAB}$ discussions of community dissemination and next steps were extremely generative, with the $\mathrm{CAB}$ bringing energy, expertise, and creativity to the design of community dissemination events; components of these events ranged from a performance by a local gospel choir to slides with study results to the creation of a paper "quilt" of personal success stories. Not surprisingly, 
determining how best to involve community members in academic dissemination was more challenging, given a lack of familiarity with the process, format, and jargon of such products, and, in some cases of a lack of interest. We found, however, that community members from the RT and a few of the community members from the $\mathrm{CAB}$ were, in fact, interested in authoring professional presentations and publications. Presentations were of particular interest when done for a community member's professional association (medical, for example, or health education). Furthermore, we were able to increase the number of community members interested in academic dissemination when we made an explicit decision that authorship did not require putting pen to paper and instead allowed people to contribute to papers by talking about their ideas in small group discussions of specific products.

Focused discussions of specific products were also successful in eliciting important input from multiple team members. For example, dissemination of lessons learned from our CBPR process benefited from both researchers and community members honestly sharing their experiences on the study and from the researchers' ability to link those experiences to common scholarly questions about the practice of CBPR. In another example, development of a manuscript on the role of SES in study recruitment, retention, and outcomes benefited from a community member's close attention to the very specific needs of lower SES participants (Silberberg et al., 2020) — in other words, her community expertise was used to address the theoretical question of how SES affected experience in the study.

\section{Discussion}

Theory can be seen as creating the container for the AAHIP DIP study, defining the general parameters of the intervention and study design. In many ways, there was an effective melding of this theoretical knowledge with community expertise. An intervention roadmap was created that combined the insights of both, and community expertise was used to modify actions and concepts suggested by theory. For example, we recognized that while bridging social capital may have benefits, it would be more effective to bring people together through existing social networks than to create support groups of previously unconnected individuals. Theory has also been an important element of data analysis, interpretation, and dissemination, as well as the later work of team members, particularly by focusing our attention on social drivers of health.

At the same time, the story of AAHIP DIP illustrates the challenges of using and melding theory with community expertise laid out in the background to this paper: the time involved and the reality of limited time, varying levels of comfort with different sources of knowledge, and the pressure to keep everybody engaged, meet community needs and demonstrate measurable impact in a short time-frame. Notably, it was not only attention to theory 
that was affected by these constraints and challenges, but also, at times, the breadth and diversity of community expertise represented in deliberations. As with theory, our capacity in this regard improved over time.

This case study provides a number of lessons for CBPR, albeit lessons that raise their own questions (see Call-Out Box 1). The first has to do with group size. Our observation is that hearing all voices and melding theory and community expertise was often easier in smaller groups - whether within the $\mathrm{RT}$ or one of the groupings that formed around dissemination or other specific tasks. The literature on team science is mixed on the size of effective teams, with tradeoffs between the communication and coordination challenges of large teams and the benefits of their diverse pool of resources; there is some indication that diverse teams (e.g., interdisciplinary teams) are more effective when smaller (Stokols et al., 2008). Our experience suggests that even when CBPR requires bringing larger groups of stakeholders together to achieve study goals, efforts to break into smaller groups can support more effective collaboration and melding of different sources of knowledge. Becker and colleagues (2013) have noted the importance of incorporating opportunities for small group deliberation into CBPR processes more generally. Chang and colleagues (2013) have noted that the commonly-used steering committee approach can fail to empower monolingual immigrant populations; this model may also need revision to support participation by English-speaking community members, especially when confronting the challenges of melding different sources of knowledge.

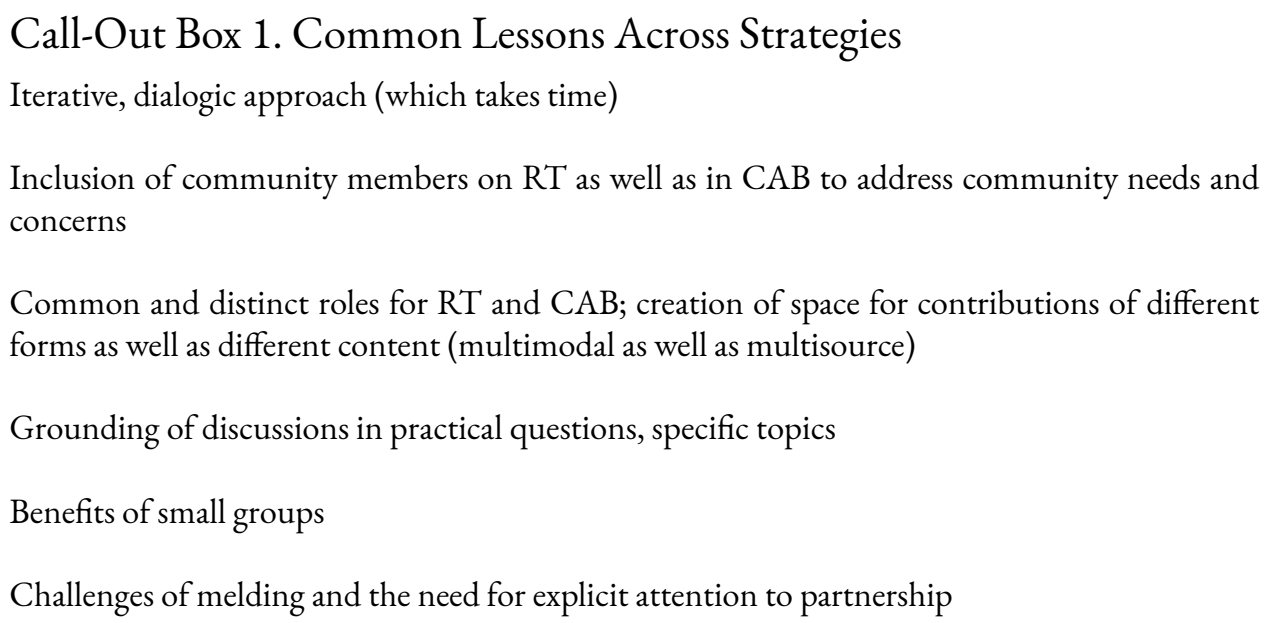

The second lesson is the benefits of the iterative, dialogic approach that evolved for our project. The RT and $\mathrm{CAB}$ played distinct roles in this process, which allowed all participants to draw on their strengths. At the same time, the inclusion of community members on the RT meant that community needs were considered at every step. This approach was particularly important in the development of an intervention that reflected both theoretical knowledge and community expertise. This aligns with other scholars' prescription that CBPR projects clearly define team members' roles, and that those roles be determined by members' strengths (Bryan et al., 2014; Drahota et al., 2016). At the same 
time, if engaging in CBPR is to enhance the capacity of all participants, and if different sources of knowledge are to be melded rather than utilized separately, role definition cannot result in the limited participation of community members that sometimes occurs (Jiménez-Chávez et al., 2018). We believe that our iterative dialogic approach can be one tool for setting realistic expectations, while still expanding capacity and benefiting from the merging of different sources of knowledge. Of course, this approach compounds the lengthy timelines associated with establishing trusting and inclusive CBPR collaborations, which is often at odds with academic tenure clocks and other institutional expectations (Springer \& Skolarus, 2019). This reinforces previous observations that promotion of effective CBPR would be well-served by changes in academic structures and processes to recognize and value the extensive work that goes into collaboration (Grieb et al., 2017).

We also learned that discussions of theory were more effective when they were focused and grounded in practical questions (e.g., whether we should form support groups across churches, a question that in theoretical terms is one of "bridging social capital"). Other students of CBPR have proposed other ways of "grounding" theoretical discussions, e.g., through photovoice (Halifax et al., 2008) and simulation games (Rossiter \& Reeve, 2008). Along similar lines, McLeroy et al. (1993), in thinking about the use of theory in health education, argue that the application of theory to practice should start with the practical problem and work backwards to what theory has to offer. Grounding does not always make it possible to advance theory or to design practice based on theoretical knowledge, given other limitations, especially those of time. Nonetheless, new insights can emerge even from discussions that do not yield exactly what was hoped.

Interestingly, it was not only some theoretical insights that were deemphasized in discussions, but also some experiential insights. On the experiential side, we found, as many CBPR researchers have (Blumenthal, 2011), that the voices of those with fewer resources were harder to access. Moreover, despite a socioecological theoretical paradigm, the focus of our intervention was individual behavior change, a decision driven primarily by the need to exhibit concrete, short-term gains to both funders and partners. We remained committed to bringing both theory and diverse community expertise to our endeavor, however, and over time, our ability to access harder-to-reach voices from both theory and the community grew as a result of our proactive attention to process.

Our case study also suggests the importance of the current focus on capacity-building for both academics and community members (Arrieta et al., 2017; Jiménez-Chávez et al., 2018), even outside the confines of a specific project. The challenges described in this case study would likely be reduced and the benefits enhanced by deliberate preparation of academic and community partners to engage in this work (see, for example, Coombe et al., 2019). 
Finally, the impact of the pressure to produce measurable results suggests the need for funders who wish to promote attention to root causes of nation-wide health disparities to develop and adhere to realistic expectations of grantees, a challenge gradually being recognized as more funders begin addressing root causes of health and other societal inequities (Paige et al., 2012).

As we write this paper, the country is reeling from the COVID-19 pandemic, its wide-ranging repercussions and disparate effects on African American, Latinx, and low-income communities, and a heightened awareness of the terrible reality of systemic racism in policing and other arenas. These developments strengthen the case for studying and supporting effective academic-community research partnerships, including enhancing the role of theory in collective action. The urgency and complexity of these problems and their wide-ranging, yet disparate, implications point to the benefits of collaborations between academic institutions and the community that can rapidly and effectively respond to these complex realities. Moreover, they point to the importance of theoretical frameworks that can help academic and community partners understand and address the root causes of the problems we face.

\section{Conclusion}

The case study presented here illustrates many of the limitations to successful melding of theoretical and experiential knowledge in CBPR: time; the need to focus on measurable, short-term changes; and differences among collaborators. Both community and theoretical voices were sometimes shortchanged - particularly voices that were more difficult to access or integrate into existing ways of operating. Nonetheless, we were able to bring theory into our work at a number of stages and meld theory with community expertise in ways that benefited our project. Our case study suggests the importance of creating opportunities for small group discussion; utilizing an iterative dialogic approach to melding theory and community expertise; grounding theoretical discussions in specific, concrete questions; taking the long view of CBPR, including purposefully bringing attention to theory; and focusing more resources on capacity building for collaboration of academic and community partners. It also reinforces the need for academic institutions and funders to align their expectations of faculty and grantees, respectively, with what it takes to effectively address the root causes of nationwide health inequities.

\section{Conflicts of Interest}

We have no known conflict of interest to disclose.

\section{Funding}

This work was supported by the National Institute for Minority Health and Health Disparities [5R24-MD001655]. 


\section{Acknowledgements}

The authors gratefully acknowledge the important contributions of all members of our research team, community advisory board, and community partners. We are also grateful to Barbara A. Israel, Ella Greene, and the anonymous reviewers from the Journal of Participatory Research Methods for their valuable insights.

Submitted: December 18, 2020 EDT, Accepted: July 28, 2021 EDT 


\section{References}

Adams, A., Miller-Korth, N., \& Brown, D. (2004). Learning to work together: Developing academic and community research partnerships. Wisconsin Medical Journal, 103(2), 15-19.

AHRQ. (2004). Community-based participatory research: Assessing the evidence. AHRQ.

Arrieta, M. I., Fisher, L., Shaw, T., Bryan, V., Hudson, A., Hansberry, S., Eastburn, S., Freed, C. R., Shelley-Tremblay, S., Hanks, R. S., Washington-Lewis, C., Roussel, L., Dagenais, P. A., Icenogle, M., Slagle, M. L., Parker, L. L., \& Crook, E. (2017). Consolidating the academic end of a community-based participatory research venture to address health disparities. Journal of Higher Education Outreach and Engagement, 21(3), 113-134.

Becker, A. B., Israel, B. A., \& Allen, A. (2013). Strategies and techniques for effective group process in CBPR partnerships. In B.A. Israel, E. Eng, A. J. Schulz, \& E. A. Parker (Eds.), Methods for Community-Based Participatory Research for Health (2nd ed., pp. 69-96). Jossey-Bass.

Bernard, P., Charafeddine, R., Frohlich, K. L., Daniel, M., Kestens, Y., \& Potvin, L. (2007). Health inequalities and place: A theoretical conception of neighbourhood. Social Science $\sigma^{\circ}$ Medicine, 65(9), 1839-1852. https://doi.org/10.1016/j.socscimed.2007.05.037

Bradbury, H., \& Reason, P. (2003). Issues and choice points for improving the quality of action research. In M. Minkler \& N. Wallerstein (Eds.), Community-Based Participatory Research for Health (pp. 201-220). Jossey-Bass.

Brakefield-Caldwell, W., Reyes, A., Rowe, Z., Weinert, J., \& Israel, B. A. (2015). Community partner perspectives on benefits, challenges, facilitating factors and lessons learned from community-based participatory research partnerships in Detroit. Progress in Community Health Partnerships: Research, Education, and Action, 9(2), 229-311.

Bryan, V., Brye, W., Hudson, K., Dubose, L., Hansberry, S., \& Arrieta, M. (2014). Investigating health disparities through community-based participatory research: Lessons learned from a process evaluation. Social Work in Public Health, 29(4), 318-334. https://doi.org/10.1080/ $\underline{19371918.2013 .821356}$

Cargo, M., \& Mercer, S. L. (2008). The value and challenges of participatory research: Strengthening its practice. Annual Review of Public Health, 29(1), 325-350. https://doi.org/10.1146/ annurev.publhealth.29.091307.083824

CDC Community Engagement Task Force. (2011). Principles of Community Engagement (2nd ed.). National Institutes of Health.

Chang, C., Salvatore, A. L., Lee, P. T., Liu, S. S., Tom, A. T., Morales, A., Baker, R., \& Minkler, M. (2013). Adapting to context in community-based participatory research: "Participatory starting points" in a Chinese immigrant worker community. American Journal of Community Psychology, 51(3-4), 480-491. https://doi.org/10.1007/s10464-012-9565-z

Chataway, C. J. (1997). An examination of the constraints on mutual inquiry in a participatory action research project. Journal of Social Issues, 53(4), 747-766. https://doi.org/10.1111/ j.1540-4560.1997.tb02459.x

Coombe, C. M., Schulz, A. J., Guluma, L., Allen, A. J., Gray, C., Brakefield-Caldwell, W., Guzman, J. R., Lewis, T. C., Reyes, A. G., Rowe, Z., Pappas, L. A., \& Israel, B. A. (2019). Enhancing capacity of community-academic partnerships to achieve health equity: Results from the CBPR partnership academy. Health Promotion Practice, 1-12.

Drahota, A., Meza, R. D., Brikho, B., Naaf, M., Estabillo, J. A., Gomez, E. D., Vejnoska, S. F., Dufek, S., Stahmer, A. C., \& Aarons, G. A. (2016). Community-academic partnerships: A systematic review of the state of the literature and recommendations for future research. The Milbank Quarterly, 94(1), 163-214. https://doi.org/10.1111/1468-0009.12184 
Ford, M., Tilley, B., \& McDonald, P. (1998). Social support among African-American adults with diabetes, part 2: A review. Journal of the National Medical Association, 90(7), 425-432.

Freeman, E. R., Brugge, D., Bennett-Bradley, W. M., Levy, J. I., \& Carrasco, E. R. (2006). Challenges of conducting community-based participatory research in Boston's neighborhoods to reduce disparities in asthma. Journal of Urban Health, 83(6), 1013-1021. https://doi.org/10.1007/ $\underline{\text { s11524-006-9111-0 }}$

Garland, A. F., Plemmons, D., \& Koontz, L. (2006). Research-practice partnership in mental health: Lessons from participants. Administration and Policy in Mental Health and Mental Health Services Research, 33(5), 517-528. https://doi.org/10.1007/s10488-006-0062-2

Gaskin, D. J., Roberts, E. T., Chan, K. S., McCleary, R., Buttorff, C., \& Delarmente, B. A. (2019). No man is an island: The impact of neighborhood disadvantage on mortality. International Journal of Environmental Research and Public Health, 16(7), 1265. https://doi.org/10.3390/ijerph16071265

Grieb, S. D., Pichon, L., Kown, S., Year, K. K., \& Tandon, D. (2017). After 10 years: A vision forward for progress in community health partnerships. Progress in Community Health Partnerships: Research, Education, and Action, 11(1), 13-22. https://doi.org/10.1353/cpr.2017.0002

Halifax, N. V. D., Yurichuk, F., Meeks, J., \& Khandor, E. (2008). Photovoice in a Toronto community partnership: Exploring the social drivers of health with homeless people. Progress in Community Partnerships for Health: Research, Education, and Action, 2(2), 129-136. https://doi.org/10.1353/cpr.0.0015

Heaney, C. A., \& Israel, B. A. (1997). Social networks and social support in health education. In K. Glanz, F. M. Lewis, \& B. K. Rimer (Eds.), Health Behavior and Health Education: Theory, Research, and Practice (2nd ed., pp. 185-209). Jossey-Bass.

Hertz, E. (2016). Pimp my fluff: A thousand plateaus and other theoretical extravaganzas. Anthropological Theory, 16(2-3), 146-159. https://doi.org/10.1177/1463499616654830

House, J. S., Umberson, D., \& Landis, K. R. (1988). Structures and processes of social support. Annual Review of Sociology, 14(1), 293-318. https://doi.org/10.1146/ annurev.so.14.080188.001453

Israel, Barbara A., Parker, E. A., Rowe, Z., Salvatore, A., Minkler, M., López, J., Butz, A., Mosley, A., Coates, L., Lambert, G., Potito, P. A., Brenner, B., Rivera, M., Romero, H., Thompson, B., Coronado, G., \& Halstead, S. (2005). Community-based participatory research: Lessons learned from the centers for children's environmental health and disease prevention research. Environmental Health Perspectives, 113(10), 1463-1471. https://doi.org/10.1289/ehp.7675

Israel, Barbara A., Schulz, A. J., Coombe, C. M., Parker, E. A., Reyes, A. G., Rowe, Z., \& Lichtenstein, R. L. (2019). Community-based participatory research: An approach to research in the urban context. In S. Galea, C. Ettman, \& D. Vlahov (Eds.), Urban Health (pp. 272-282). Oxford University Press. https://doi.org/10.1093/oso/9780190915858.003.0029

Israel, Barbara A., Schulz, A. J., Parker, E. A., \& Becker, A. B. (1998). Review of community-based research: Assessing partnership approaches to improve public health. Annual Review of Public Health, 19(1), 173-202. https://doi.org/10.1146/annurev.publhealth.19.1.173

Jagosh, J., Macaulay, A. C., Pluye, P., Salsberg, J., Bush, P. L., Henderson, J., Sirett, E., Wong, G., Cargo, M., Herbert, C. P., Seifer, S. D., Green, L. W., \& Greenhalgh, T. (2012). Uncovering the benefits of participatory research: Implications of a realist review for health research and practice. Milbank Quarterly, 90(2), 311-346. https://doi.org/10.1111/j.1468-0009.2012.00665.x 
Jiménez-Chávez, J. C., Rosario-Maldonado, F. J., Torres, J. A., Ramos-Lucca, A., Castro-Figueroa, E. M., \& Santiago, L. (2018). Assessing acceptability, feasibility, and preliminary effectiveness of a community-based participatory research curriculum for community members: A contribution to the development of a community-academic research partnership. Health Equity, 2(1), 272-281. https://doi.org/10.1089/heq.2018.0034

Jones, L., \& Wells, K. (2007). Strategies for academic and clinician engagement in communityparticipatory partnered research.JAMA, 297(4), 407. https://doi.org/10.1001/jama.297.4.407

Lucero, J., Wallerstein, N., Duran, B., Alegria, M., Greene-Moton, E., Israel, B., Kastelic, S., Magarati, M., Oetzel, J., Pearson, C., Schulz, A., Villegas, M., \& White Hat, E. R. (2018). Development of a mixed methods investigation of process and outcomes of community-based participatory research. Journal of Mixed Methods Research, 12(1), 55-74. https://doi.org/10.1177/1558689816633309

Macaulay, A. C., Jagosh, J., Seller, R., \& Henderson, J. (2011). Assessing the benefits of participatory research: A rationale for a realist review. Global Health Promotion, 18(2), 45-48. https://doi.org/ $\underline{10.1177 / 1757975910383936}$

McLeroy, K., Steckler, A., Simons-Morton, B., Goodman, R., Gottlieb, N., \& Burdine, J. (1993). Social science theory in health education: Time for a new model. Health Education, 8, 305-312.

Paige, S. B., Bourcier, E., Cahill, C., Hsu, C., \& Kabel, C. (2012). Evaluating the Kaiser Permanente Community Fund's social determinants of health portfolio. The Foundation Review, 4(1), 68-80. https://doi.org/10.4087/foundationreview-d-11-00030

Przeworski, A., \& Teune, H. (1970). The Logic of Comparative Social Inquiry. Wiley Interscience, John Wiley \& Sons.

Putnam, R. (2001). Bowling Alone: The Collapse and Revival of American Community. Simon and Schuster.

Rossiter, K., \& Reeve, K. (2008). The last straw! A tool for participatory education about the social drivers of health. Progress in Community Partnerships for Health: Research, Education, and Action, 2(2), 137-144. https://doi.org/10.1353/cpr.0.0017

Sallis, J. F., Owen, N., \& Fisher, E. B. (2008). Ecological models of health behavior. In K. Glanz, B. K. Rimer, \& K. Viswanath (Eds.), Health Behavior and Health Education (4th ed., pp. 465-485). John Wiley \& Sons, Inc.

Silberberg, M., Muhlbaier, L. H., Hart-Brothers, E., Weaver, S. M., \& James, S. A. (2020). The role of socioeconomic status in a community-based study of diabetes secondary prevention among African Americans. International Journal of Health Promotion and Education, 1-11. https://doi.org/ $\underline{10.1080 / 14635240.2020 .1866999}$

Skocpol, T. (1995). Social Policy in the United States: Future Possibilities in Historical Perspective. Princeton University Press.

Springer, M. V., \& Skolarus, L. E. (2019). Community-based participatory research: Partnering with communities. Stroke, 50(3), e48-e50. https://doi.org/10.1161/strokeaha.118.024241

Stokols, D. (1992). Establishing and maintaining healthy environments: Toward a social ecology of health promotion. American Psychologist, 47(1), 476-498. https://doi.org/10.1037/ 0003-066x.47.1.6

Stokols, D., Misra, S., Moser, R. P., Hall, K. L., \& Taylor, B. K. (2008). The ecology of team science: Understanding contextual influences on transdisciplinary collaboration. American Journal of Preventive Medicine, 35(2 Suppl), S96-S115. https://doi.org/10.1016/j.amepre.2008.05.003

Wallerstein, N. B., \& Duran, B. (2003). The conceptual, historical and practice roots of communitybased participatory research and related participatory traditions. In M. Minkler \& N. Wallerstein (Eds.), Community Based Participatory Research for Health (pp. 27-52). Jossey-Bass. 
Wallerstein, N. B., \& Duran, B. (2006). Using community-based participatory research to address health disparities. Health Promotion Practice, 7(3), 312-323. https://doi.org/10.1177/ $\underline{1524839906289376}$

Wallerstein, N. B., Duran, B., Minkler, M., \& Foley, K. (2005). Developing and maintaining partnerships with communities. In B.A. Israel, E. Eng, A. J. Schulz, \& E. A. Parker (Eds.), Methods in Community-Based Participatory Research for Health (pp. 31-72). Jossey-Bass.

Williams, D. R., \& Jackson, P. B. (2005). Social sources of racial disparities in health. Health Affairs, 24(2), 325-334. https://doi.org/10.1377/hlthaff.24.2.325 